\title{
A staff/student partnership for bringing the One-Minute Paper into the digital age
}

Paula S. Karlsson, Alison Gibb, Paul Ferri

University of Glasgow

\section{Introduction}

This article outlines our project, carried out by a partnership of three Management lecturers and ten third-year Computing Science students, to transpose the One-Minute Paper (OMP) teaching feedback tool (Draper, 2003) from its traditional paper-based version into a digital format: a digital One-Minute Paper (DOMP).

Whilst it is always challenging to gather real-time, actionable feedback from students because of increasingly-large class sizes and a very diverse international student body, to do so has never been more important. It can be difficult to tell what our students are absorbing and whether they understand the key concepts we are trying to teach them. With large classes, there is limited opportunity for one-to-one conversations with students and students are not likely to raise any concerns they may have in class when surrounded by their peers.

To tackle this issue, and with the ultimate aim of improving the student experience, we started experimenting with the OMP. The basic premise of the OMP tool centres upon asking students variations of the following three questions:

1. What was the most important thing you learned during today's class?

2. Was there something you did not understand that you would like explained more clearly?

3. Was there anything you wanted to find out more about, that was or was not covered?

The OMP is a formative classroom assessment and feedback technique that benefits both students and lecturers. It can be used by lecturers to identify instances where they have not been clear in their teaching or where the topic covered has been difficult for students to grasp. It allows students to reflect briefly on the topic that has been covered and assess their own learning. Ultimately, it enables lecturers to address swiftly the issues that need further clarity (Draper, 2003; Stead, 2005).

\section{Staff/student partnership}

\section{The background to the project}

As a teaching team, we experimented with different formats of the OMP during the 20162017 academic year. The team includes a senior lecturer (with extensive industry experience gathered prior to transferring into academia) and two lecturers who have recently started their first academic posts (one who came directly from postgraduate studies and one who came from industry). All of us are on contracts focused on learning and teaching and are therefore expected to engage in scholarship activities, but we all had personal reasons for developing this particular stream of activity. For instance, the 'new' lecturers wanted to develop their teaching practice continuously from the start of their teaching. 


\section{Case Studies}

The first phase of our research with the OMP highlighted some challenges with the traditional paper application. The paper-based version of the OMP may not, in a digital world, be the best option for enhancing the student experience, especially in large-class teaching, where, since it takes a long time to analyse the feedback, timely action in response is somewhat difficult. What we needed was a quick tool to collect and analyse the data: digitisation would allow us to overcome the challenges.

When we started our research with the OMP, a new classroom technology YACRS (Yet Another Class Response System) for eliciting student feedback was introduced by our University. YACRS was designed to replace the use of traditional 'clickers' in classroom situations where the lecturer wants the entire class to respond to certain questions. Students are able to use any networked device to respond to the questions, with responses shown instantly on the tutor's screen. After trials of the YACRS system as a way of digitising the OMP with some of our classes, it became clear that its functionality was deficient in terms of staying true to the qualitative nature of the OMP. As YACRS limited teaching staff to asking mainly multiple-choice questions (MCQs), it therefore needed to be developed to allow large text input and to include an analytical component that could identify key themes from the student inputs. This would reduce the time taken by the lecturer to analyse the student inputs and result in real-time feedback and action. If this functionality could be added, it could prove to be a very powerful tool. In addition, because some staff were reluctant to use the YACRS software as they found it challenging and unintuitive, improvements to its usability were therefore also envisaged.

We started exploring the YACRS tool by speaking to its developer, asking specifically about the possibility of adding an OMP feature to it. The developer explained that the software was his 'pet project' and that any further development would occur as and when he would have time to 'play around with it'. This being the case, the idea was floated that we might secure the services of a Computing Science student to modify the software to suit our purposes. We contacted the Computing Science department in the spring of 2017 and were informed that there was a third-year course during which student groups worked on a project for external clients; we were encouraged to put forward a proposal for just such a project.

\section{The start of the project}

In September 2017, the teaching team embarked on a partnership with two groups of students (ten students in total, studying for Computing Science degrees) who are, at the time of writing, working on redesigning YACRS as part of their Software Team Project course which runs between October 2017 and March 2018. The rationale behind the course is that students collaborate with external customers to carry out an approved live project, in order to experience as nearly as possible what it's like to work in a real-world context. Customers are expected to meet their student teams monthly, on six days throughout the course, but can also meet more frequently and engage with teams in such other ways as site visits (Simpson and Storer, 2017).

The project brief given to students was that they needed to modify YACRS so that it could also process qualitative feedback, highlighting common themes. This way, the tool could be used to improve teaching through feedback addressed in real time, allowing issues to be dealt with immediately and more efficiently and thus benefiting the incumbent student cohort, 


\section{Case Studies}

which would otherwise have to wait for feedback until the end of the course. A secondary objective was to make YACRS easier to use.

After our first full-day session, where the brief was discussed in more detail and the students were able to ask questions, we arranged a meeting - at the half-way point before the next client day - at which we demonstrated the use of YACRS with the DOMP in a seminar room. Our intention was to replicate how we would set it up and run it in our normal classes, in order to show the students where the problem areas lie, demonstrate what we are trying to achieve with the system and engender a deeper understanding of our requirements by a means much clearer than mere explanation of them.

\section{Student perspectives}

At the start of the project, the majority of our Computing Science students were confident that they would achieve all or most of the objectives we had set them in redesigning YACRS. From the students' point of view, very few things work well in YACRS - a matter of concern, since we wish not only for teachers other than ourselves to use it, but also for students to engage with it. The Computing Science students' opinion might be somewhat skewed, as they know the ins and outs of computer technology, but, as frequent users of the system in class, they should still have their views respected as the voice of the student body. After our first meeting with them, their excitement about it (and their despair at the current system!) was palpable.

The student groups had to bid for their desired project. Interestingly, our project was, out of the choices available, the first one of both student groups with whom we are currently working. For example, one student commented that this was because we (the teachers) had a really good idea of what we were wanting from the system, we looked very interested in the project and, so it seemed to the students, "we cared" about the student learning experience. In addition, improving the system would be really relevant to these students as they are already using it in many of their classes. Another student said that, because they had used YACRS before, they were "stepping into familiar ground, but they could also see the direct result of it', which would be unlike working on a project with an external partner, where the students would never themselves get to use the software.

One of the immediate results of the project has been that students have found, in the current software, some security breaches which we are now able to bring to the attention of the University. As one student stated: "The security of YACRS is that there is no security", which simply is not good enough when, for example, staff are using it for assessment purposes.

The students have been keen to show their progress. For instance, one of the groups wanted the teachers to test its prototype halfway through the project, because "they have a number of known bugs, but they want to see if we can find anymore bugs". One such bug was found when the students were unable to work out why one of the teachers could not log into the prototype software. They wondered whether a non-English character was used in the login details (the teacher has a non-English name), though this was not the case. The error quickly emerged when the teacher pointed out that she has a hyphen in her name. Finding possible bugs was a trial-and-error process, requiring the coming together of both students and staff to work on the prototype and discuss the project in detail. 


\section{Case Studies}

For the analysis element of the brief, the students have been encouraged by their Computing Science supervisors to use existing expertise at the University. It has been critical for the project that the students have support from the Computing Science department, as their staff members can ask the difficult software-related questions which we don't have the knowledge to formulate.

Overall, the students seem hungry to deliver improvements to YACRS, both for their own benefit and for ours as teachers, now that they fully understand the challenges of working with a system that does not completely meet teachers' needs. They can see the benefit that fully-optimised software could have on their peers across the University, a factor which is proving to be highly motivating.

\section{Teaching Issues}

One of the issues we as teachers had not considered was the need for an extensive wifi network across the institution if the modified YACRS system is to work optimally. Previous research has found this to be a problem when using personal wifi-enabled devices (Katz et al., 2017). The Computing Science students brought this to our attention, as they use YACRS more than we do: it is built into much of their course assessment and their experience is that, once the class size grows over approximately fifty students, the system is unable to handle it, the wifi becomes patchy and students are unable to access the questions. As we especially want to use the DOMP in our large classes, this is something that needs to be considered when redesigning the technology at institution level and is something we would not have known had it not been for the staff/student partnership. The students did reflect that the system responded better when they remained anonymous and did not have to log in with their student IDs. However, if the tool is to continue to be used for $M C Q$ in class assessment, the option of identifying students via login must remain, even if this is an unnecessary feature for teachers who wish to use it for the DOMP purposes.

Ethics is another issue we took for granted going into this partnership. We assumed that, as the teaching team had ethical approval for the project, the students would be covered within this if they were to test their prototypes with actual users. However, this transpired to pose some challenges, as it was not as straightforward as we might have expected at our institution.

It is not the first time that staff/student partnerships have been created in Higher Education $(\mathrm{HE})$ : it is something the Higher Education Academy is promoting and our own institution has recently launched a funding scheme to help develop such projects. For instance, Elphick and Sims (2017) showed how staff have been supported and trained by students in the use of technology in classrooms. Though the partnerships they discussed were relatively collaborative, there was often still a divide between the lecturer and student. To achieve authentic partnership, this needs careful consideration: it can lead to and facilitate a bottomup change in power relationships in universities, with both staff and students becoming active in the learning community. Whilst, in our case, the partnership indeed consists of lecturers and students, we are not the direct lecturers of these particular students who are working on our YACRS project; nor are we involved in grading their performance in the course. In practice, we are external customers, just as someone from the private, public or third sector would be. As most of us have limited knowledge of the inner workings of computer technology and software development, we certainly do not see ourselves as being 


\section{Case Studies}

in a power position in relation to our teams of students. Our student partners have a direct input into the pedagogic research we are undertaking as part of developing and testing the DOMP methodology and, if successful in achieving the objectives of the project, they can be involved in delivering real change within our institution. Hence, equal partnership, from a power-relationship perspective, is vital for us.

Halfway through the process, it became clear that one of the student groups had misunderstood part of the project brief. This was an unfortunate turn of events, and one that we, were we external clients - for example from a private sector organisation - would not accept; we might well withhold payment, were it an actual business transaction. However, as we - the clients - are all teachers, and as part of our wider OMP project is to test student understanding and develop ourselves pedagogically, we have a responsibility to support the students in their learning process and try to overcome this issue. This is a point that one should bear in mind if embarking on a staff/student partnership: the students remain students (whether we are external clients or not) and they are effectively in a dependent relationship to us, as their grades depend on the project's success (not merely the outcome, but the entire process).

We also found a difference in mind sets as the students seemed happy to produce this software and hand it over to the teaching team (and by extension, the University). Thinking about the ownership of the software was not high on the students' agenda. However, as the teaching team consists of Management lecturers, we had to urge them to be careful regarding copyright and consider how they would manage this in the longer term.

Overall, we have been impressed by the level of work the student groups have put into the project and the prototypes they have developed for the new enhanced YACRS and we are excited to show the outcome of our staff/student partnership for bringing the One-Minute Paper into the digital age.

\section{Concluding remarks}

We would encourage anyone who is presented with the opportunity to work with students from an applied subject to seize it. If we just sat and grumbled about the negatives of YACRS, nothing would ever change. Our staff/student partnership continues and, at this precise point in time, we do not know if it will lead to the desired outcomes - in other words, that we have a classroom response system that: a) incorporates a quick analytical tool allowing us to ask qualitative OMP-type questions in large classes where we have limited time to work through the responses; b) is easier to use. However, once the partnership project is finished, we shall either have a system that works for us, or we shall know that we need to try some other avenue, instead of wasting our time with a system that will not do what we want. Regardless of the outcome, we have engaged with ten highly-competent and enthusiastic students who have provided us as teachers with an invaluable experience. Furthermore, the output of this project may, over time, also benefit the wider University community.

\section{Reference list}

Draper, S. (2003) One-minute papers. January, Department of Psychology, University of Glasgow. Available at: http://www.psy.gla.ac.uk/ steve/resources/tactics/minute.html (Accessed: 10 August 2017). 


\section{Case Studies}

Elphick, M. and Sims, S. (2017) 'Reflections on developing Technology-Enhanced Learning through staff-student partnership - a case study of using mobile devices cross-institutionally.' Journal of Educational Innovation, Partnership and Change, 3(1). Available at:

https://journals.gre.ac.uk/index.php/studentchangeagents/article/view/573 (Accessed: 3 November 2017).

Katz, L., Hallam, M.C., Duvall, M.M. and Polsky, Z. (2017) 'Considerations for using personal Wi-Fi enabled devices as clickers in a large university class.' Active Learning in Higher Education, 18(1), 25-35. Available at:

http://journals.sagepub.com/doi/abs/10.1177/1469787417693495 (Accessed:15 October 2017).

Simpson, R. and Storer, T. (2017) Experimenting with Realism in Software Engineering Team Projects: An Experience Report. 30th IEEE Conference on Software Engineering Education and Training (CSEE\&T), Savannah, GA, USA, 7-9 November 2017.

Stead, D.R. (2005) 'A review of the one-minute paper.' Active Learning in Higher Education, 6(2), 118-131. Available at:

http://journals.sagepub.com/doi/abs/10.1177/1469787405054237 (Accessed: 10 August 2017). 